\title{
A Change in Bathing Style May Improve Mental Fitness
}

\author{
Takaaki Kubo1*, Tomonori Yasuda', Yoshihisa Masumitsu', Yoshihiro Iwashita1, \\ Satoshi Watanabe ${ }^{2}$, Taichi Ishizawa2 ${ }^{2}$, Mitsuo Tsunakawa ${ }^{2}$, Shingo Yano², Junichi Iimaya1 \\ ${ }^{1}$ Department of Rehabilitation, Faculty of Health Sciences, Kumamoto Health Science University, Kumamoto, \\ Japan \\ ${ }^{2}$ Products Development Department, Bathclin Corporation, Ibaraki, Japan \\ Email: ${ }^{*}$ kubo@kumamoto-hsu.ac.jp
}

Received 24 January 2015; accepted 13 February 2015; published 16 February 2015

Copyright (C) 2015 by authors and Scientific Research Publishing Inc.

This work is licensed under the Creative Commons Attribution International License (CC BY).

http://creativecommons.org/licenses/by/4.0/

(c) (†) Open Access

\section{Abstract}

Frequent bathtub bathing (BB) improves the mental health of middle-aged and older Japanese individuals. This study investigated the chronic mental health effects of $B B$, maintaining warmth using an insulating sheet and sleeping bag after bathtub bathing (BBW), and bathtub bathing with herbal extracts (BBH) in healthy young adults. The study involved healthy young adults who habitually showered, as opposed to bathing. In the first experiment, 18 participants were randomly assigned to either the BB or BBW groups for 14 consecutive nights. After a 2-week washout period, the participants were asked to switch their bathing styles (a cross-over design). In the second experiment, 20 participants were randomly assigned to the BB or BBH group. The herbal extracts for the BBH group contained angelicae radix, aurantii nobilis pericarpium, chamomile, and zingiberis rhizoma. After a 2-week washout period, these participants also switched to the other bathing style. The participants' mental conditions pre- and post-intervention were assessed using the Profile of Mood States-Brief Form questionnaire, Japanese version, and were statistically analyzed. The participants' Anger-Hostility score converged to an average (50 points) in the post-BBW and post-BBH participants, and there were no significant differences in $B B$. The Confusion change rate was significantly different in the first experiment (BB versus BBW). The Depression-Dejection and Fatigue change rates were significantly different in the second experiment (BB versus $B B H$ ). Our findings suggest that changing bathing style from showering to BBW or BBH improves the POMS Anger-Hostility scores of healthy young adults.

\section{Keywords}

Bathtub Bathing, Warmth, Herbal Extracts, Mental Fitness, Healthy Young Adults

\footnotetext{
*Corresponding author.
}

How to cite this paper: Kubo, T., Yasuda, T., Masumitsu, Y., Iwashita, Y., Watanabe, S., Ishizawa, T., Tsunakawa, M., Yano, S. and limaya, J. (2015) A Change in Bathing Style May Improve Mental Fitness. Health, 7, 270-278. 


\section{Introduction}

The characteristics of most mental disorders in young people arise during youth (12 - 24 years of age) [1]. Hunt et al. [2] reported the results of questionnaire data from students at 26 colleges and universities in the United States in 2007 and 2009, revealing a number of mental health problems, such as depression and anxiety disorders. In Japan, Uchida [3] reported that apathetic and withdrawn students at 49 Japanese national universities were those more likely to leave university, take time off, or repeat academic years; the rate of these events in Japan has been increasing for the past 21 years. Most students with student-apathy display an informal syndrome that is often accompanied by symptoms of depression and anxiety.

Bathing is a habit of Japanese people for cleansing and refreshing oneself. Bathtub bathing (BB) has also been reported to affect mental health. For example, Ishizawa et al. [4] reported that frequent BB improves the mental health of middle-aged Japanese individuals, and Hayasaka et al. [5] reported similar results for elderly Japanese individuals. Additionally, bathing with herbal extracts increases peripheral blood circulation, helping to maintain body warmth after bathing, and providing a feeling of relief among middle-aged Japanese individuals [6]-[9].

A questionnaire survey on bathing behavior was conducted in the Kinki area of Japan, involving 581 Japanese individuals of all ages. The results indicated that $60 \%$ of the respondents habitually showered in the summer, as opposed to having a bath, whereas that number declined to $17 \%$ during the winter. Additionally, the study found that the younger the respondent, the more likely they were to shower (70\%) in the summer, and that $33 \%$ of the 10 - 20-year-old individuals only showered, even in the winter [10]. Therefore, BB was hypothesized to have a greater effect on the mental health conditions of younger individuals, compared with older individuals who were already more likely to have a bath, rather than shower.

This study investigated the chronic effects of three bathing styles, BB, maintaining warmth with an insulated sheet and sleeping bag after bathtub bathing (BBW), and bathtub bathing with herbal extracts (BBH), on the mental health condition (i.e., mood states) of healthy, young adults.

\section{Methods}

\subsection{Participants}

The first experiment involved 18 (6 males, 12 females) healthy young adults (mean age, $19.6 \pm 0.7$ years; mean \pm SD) who habitually took showers, as opposed to bathing. In the second experiment, 20 (8 males, 12 females) healthy young adults (mean age, $21.3 \pm 1.6$ years), with similar hygiene habits as those in experiment 1 , participated. Individuals with the following conditions were excluded from the study: orthostatic hypotension, skin disease, acute disease, active tuberculosis, malignant tumors, heart disease, respiratory failure, renal failure, bleeding disease, severe anemia, pregnancy, and arteriosclerosis. Written informed consent was obtained from each participant prior to participation in these studies; the study was approved by the Ethics Committee of Kumamoto (Japan) Health Science University (Permit Number: 24 - 56 and 25 - 34)

\subsection{Experimental Design and Protocol}

In experiment 1, participants were randomly assigned to one of two groups (each with 3 males and 6 females). The participants were directed to BB, each night for 14 consecutive nights; one group spent an additional 30 min keeping warm after BB. Following a 2-week washout period, the participants were asked to switch their bathing style and repeat the 14-day study. This experiment was conducted between November 2012 and December 2012 (Figure 1). Experiment 1 had two styles, and involved BB as described by liyama et al. [11]. The participants immersed their bodies, up to the supraclavicular level, for $10 \mathrm{~min}$ in tap water adjusted to a temperature of $41^{\circ} \mathrm{C}$, in their home bathtub; the water temperature was measured using a digital temperature indicator. The BBW participants were instructed to stay warm for an additional $30 \mathrm{~min}$., in a static supine position, in a room adjusted to temperature of $25^{\circ} \mathrm{C}$, while wrapped in a thermal insulating sheet and sleeping bag.

In experiment 2, the participants were randomly assigned into one of another two groups (each with 4 male and 6 female participants). One group was instructed to BB, nightly for 14 consecutive nights, and the other group was instructed to $\mathrm{BB}$, after adding $15 \mathrm{~mL}$ of herbal extract (containing angelicae radix, aurantii nobilis pericarpium, chamomile, and zingiberis rhizoma extracts) for the same period of time (BBH). Following a 2-week washout period, the participants were asked to switch their bathing style, and repeat for another 14 consecutive days. This experiment was conducted between October 2013 and November 2013 (Figure 2). 


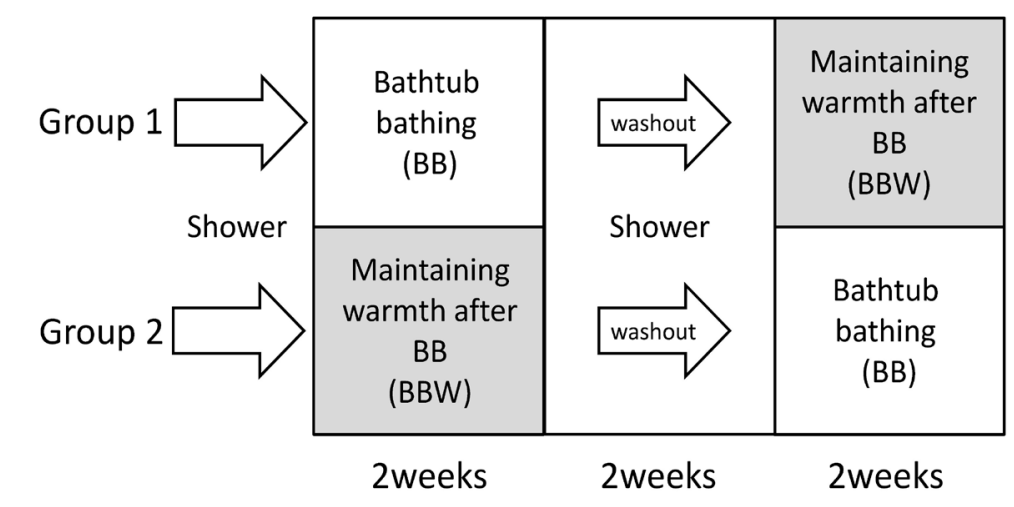

Figure 1. Flow diagram of experiment 1 (cross-over design).

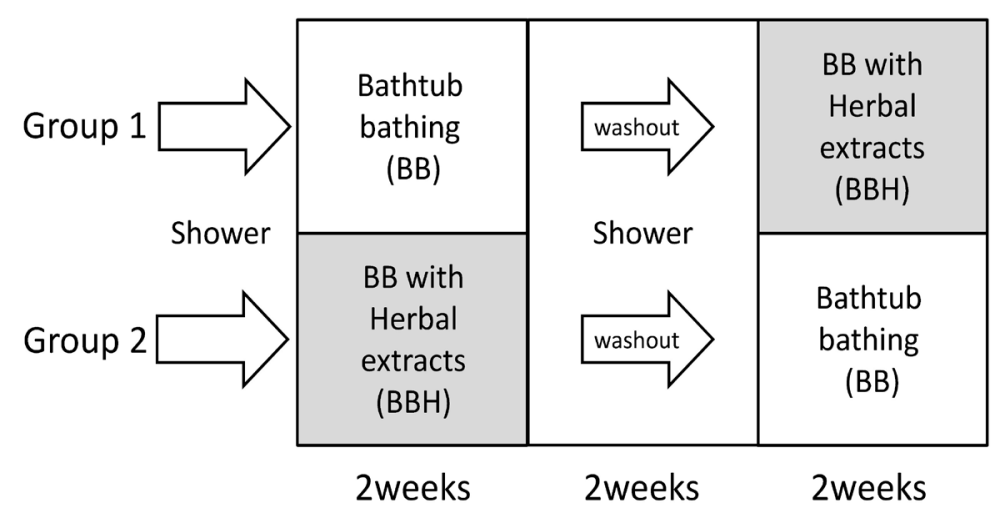

Figure 2. Flow diagram of experiment 2 (cross-over design).

\subsection{Measurements}

The participants' mental conditions were assessed using the Profile of Mood States (POMS)-Brief Form questionnaire, Japanese version. The POMS comprises 6 scales assessing Tension-Anxiety, Depression-Dejection, Anger-Hostility, Vigor, and Fatigue, and was administered 4 times during the 6-week period of each experiment (i.e., before and after the first bathing style, and before and after second bathing style).

\subsection{Data Analysis}

The T-scores and change rates were calculated using a scale-by-scale examination of the raw scores for each aspect of the POMS. Formula (1) shows the calculation of the T-score. The T-score is a standardized score, and scores between 40 and 60 indicate a healthy mental status. Furthermore, a "standard mood" is considered to represent the $\mathrm{T}$-scores converging towards a 50 -point score.

$$
\mathrm{T}-\text { score }=50+10 \times(\text { raw score }- \text { mean score }) / \mathrm{SD}
$$

In this paper, the differences between the standardized 50 points and the actual T-score are described as delta $50(\Delta 50)$, which represents the absolute value of 50 points - the T-score of each POMS scale (Formula (2)).

$$
\mid 50-\mathrm{T} \text {-score } \mid=\Delta 50
$$

The change rates for each of the 6 scales associated with each bathing style were also calculated. Formula (3) shows the calculation of the change rate for $\mathrm{BB}$, as an example; BBW and $\mathrm{BBH}$ were calculated similarly. The change rates for BBW and BB were compared in experiment 1, and BBH and BB were compared in experiment 2 .

$$
((\text { postBB }- \text { preBB }) / \text { preBB }) \times 100
$$




\subsection{Statistical Analysis}

Statistical analyses were performed using R2.8.1 (http://www.r-project.org/). The effect of time (i.e., pre-intervention versus post-intervention) was analyzed using a paired t-test. The effect of bathing style (i.e., BB versus $\mathrm{BBW}$, and BB versus BBH) was analyzed using Wilcoxon's signed rank sum test. In all analyses, the criterion for statistical significance was $5 \%$.

\section{Results}

\section{1. $\Delta 50$ in Experiment 1}

The postBB Tension-Anxiety score converged on the 50-point mark, compared with preBB; there were no significant differences among the other scales during the BB portion of the study (Figure 3). In the BBW style, the Anger-Hostility also converged on the 50-point mark after BBW, compared with preBBW; there were no significant differences among the other scales (Figure 4).

\section{2. $\Delta 50$ in Experiment 2}

There were no significant differences among the 6 scales for BB (Figure 5). The Anger-Hostility score con-

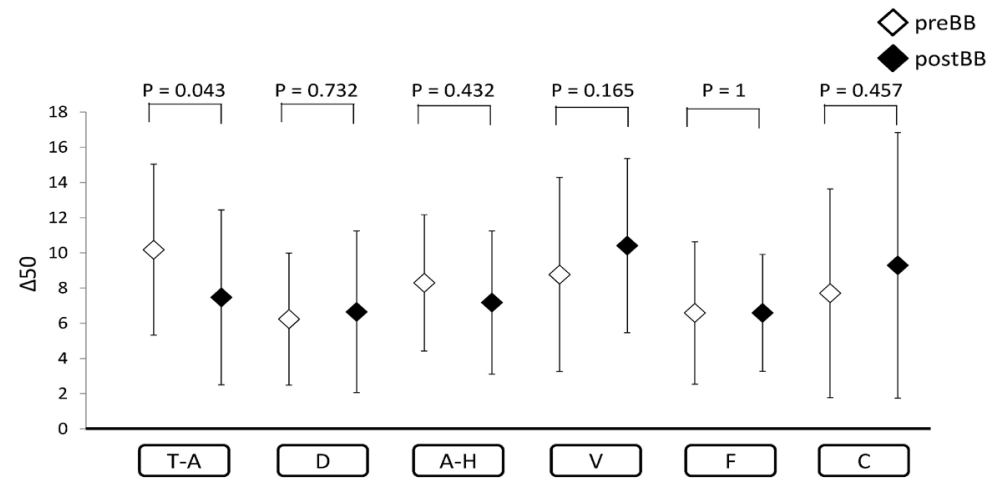

Figure 3. Delta 50 results for bathtub bathing (BB) in experiment 1 . White diamonds show the preBB (mean $\pm \mathrm{SD}$ ) scores; black diamonds show the postBB (mean $\pm \mathrm{SD}$ ) scores for each Profile of Mood States scale. A score of "0" on the Y-axis represents a T-score of 50 points. T-A, Tension-Anxiety; D, Depression-Dejection; A-H, Anger-Hostility; V, Vigor; F, Fatigue; C, Confusion.

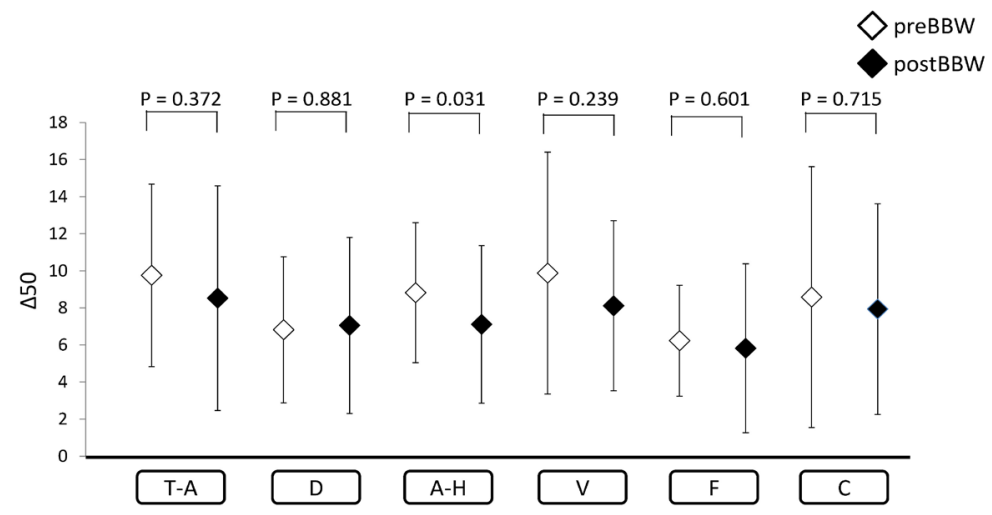

Figure 4. Delta 50 results for bathtub bathing, with warming (BBW), in experiment 1 . White diamonds show the preBBW (mean $\pm \mathrm{SD}$ ) scores; black diamonds show the postBBW (mean \pm SD) scores for each Profile of Mood States scale. A score of " 0 " on the Y-axis represents a T-score of 50 points. T-A, Tension-Anxiety; D, Depression-Dejection; A-H, Anger-Hostility; V, Vigor; F, Fatigue; C, Confusion. 
verged on the 50-point mark, postBBH, compared with preBBH; there were no significant differences in the other scales for BBH (Figure 6).

\subsection{Change Rates in Experiments 1 and 2}

The Confusion change rate was significantly different in experiment 1, only (Figure 7). The Depression-Dejection and Fatigue change rates were significantly different only in experiment 2 (Figure 8).

\section{Discussion}

These studies, involving a simple change from showering to taking tub baths, were conducted to investigate the effects of three bathing styles, BB, BBW, and BBH, on the mental conditions of healthy young adults.

A normalizing phenomenon occurs for various physiological factors when they converge to a certain value because of a non-specific modulatory action, such as serial immersion in a hot springs. Jordan et al. [12]-[14] reported such a normalizing phenomenon for measured values of body weight, blood pressure, heart rate, and

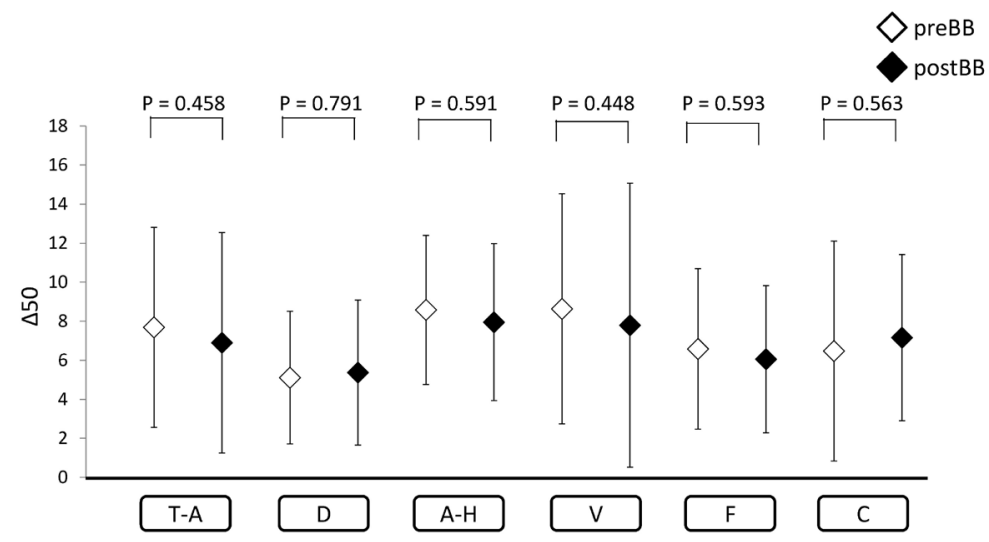

Figure 5. Delta 50 results for bathtub bathing (BB) in experiment 2. White diamonds show the preBB (mean $\pm \mathrm{SD}$ ) scores; black diamonds show the postBB (mean \pm SD) scores for each Profile of Mood States scale. A score of " 0 " on the Y-axis represents a T-score of 50 points. T-A, Tesion-Anxiety; D, Depression-Dejection; A-H, Anger-Hostility; V, Vigor; F, Fatigue; C, Confusion.

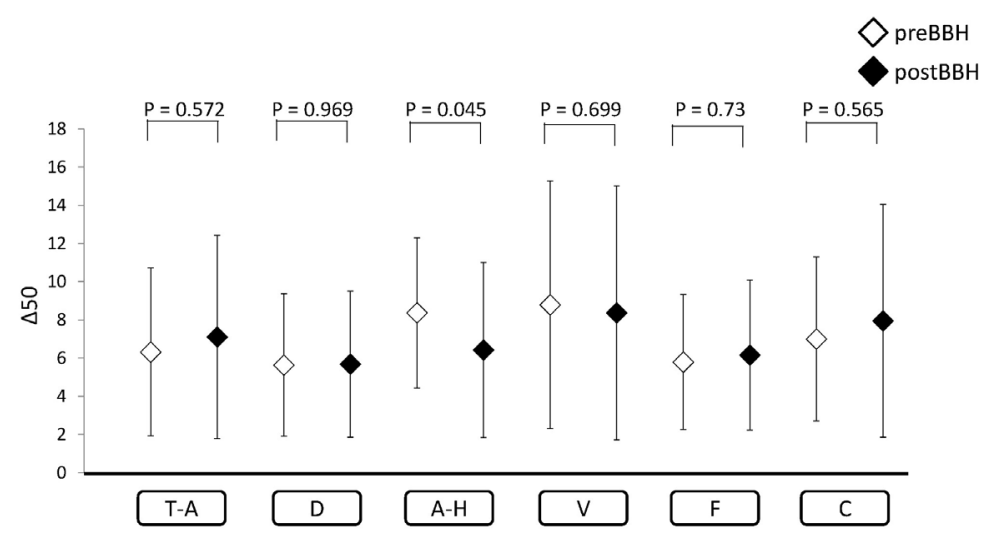

Figure 6. Delta 50 results for bathtub bathing, with herbal extracts (BBH), in experiment 2. White diamonds show the preBB (mean $\pm \mathrm{SD}$ ) scores; black diamonds show the postBB (mean \pm SD) scores for each Profile of Mood States scale. A score of " 0 " on the Y-axis represents a T-score of 50 points. T-A, Tension-Anxiety; D, Depression-Dejection; A-H, Anger-Hostility; V, Vigor; F, Fatigue; C, Confusion. 


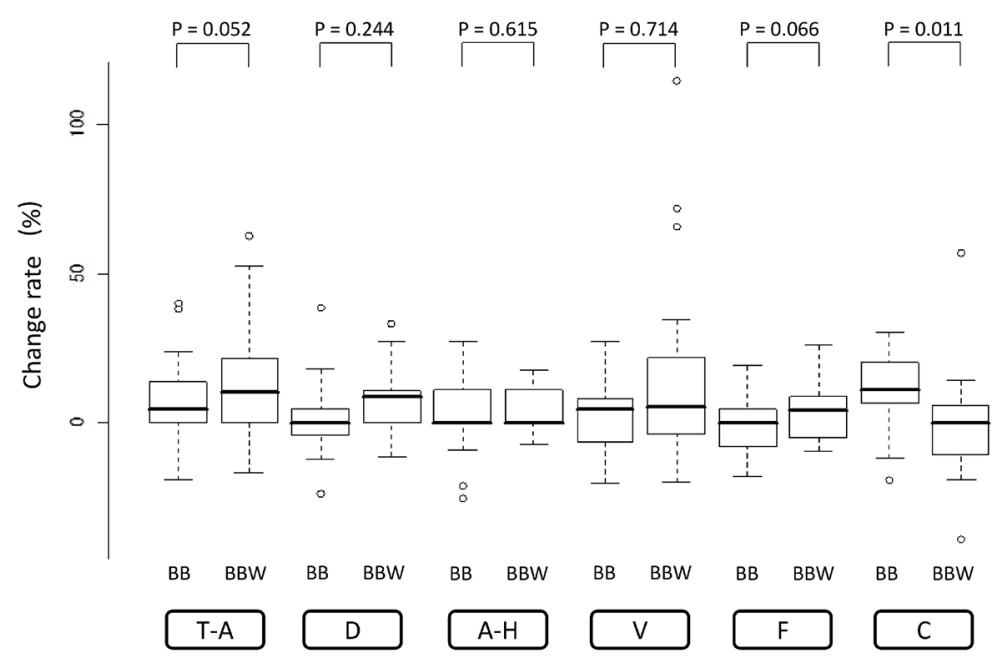

Figure 7. Change rate results for experiment 1. Explanation of Box-andwhisker plots: upper horizontal line of box, 75th percentile; lower horizontal line of box, 25th percentile; horizontal bar within box, median; upper horizontal bar outside box, smaller than "75th percenttile + $1.5 \times$ IQR"; lower horizontal bar outside box, larger than "25th percentile $-1.5 \times$ IQR". Circles represent outliers. IQR, Inter Quartile Range; T-A, Tension-Anxiety; D, Depression-Dejection; A-H, Anger-Hostility; V, Vigor; F, Fatigue; C., Confusion, BB; Bathtub bathing, BBW; Maintaining body warmth after bathtub bathing.

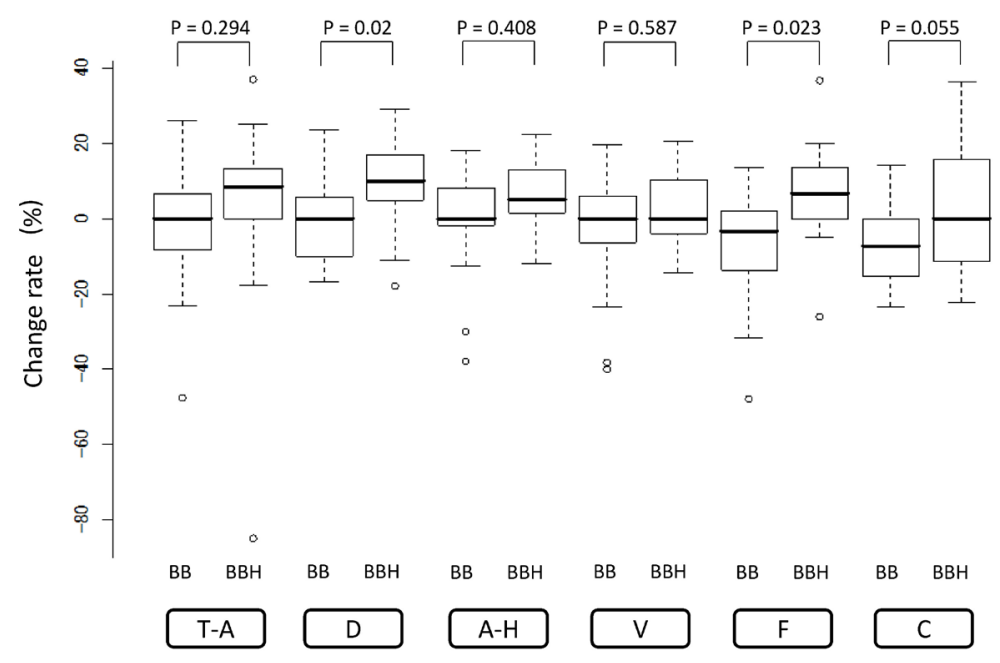

Figure 8. Change rate results for experiment 2. Explanation of Box-andwhisker plots: upper horizontal line of box, 75th percentile; lower horizontal line of box, 25th percentile; horizontal bar within box, median; upper horizontal bar outside box, smaller than "75th percentile + $1.5 \times$ IQR"; lower horizontal bar outside box, larger than "25th percentile $-1.5 \times$ IQR". Circles represent outliers. IQR, Inter Quartile Range; T-A, Tension-Anxiety; D, Depression-Dejection; A-H, Anger-Hostility; V, Vigor; F, Fatigue; C., Confusion, $\mathrm{BB}$; Bathtub bathing, $\mathrm{BBH}$; Bathtub bathing with herbal extracts.

breathing rate. The measured values showed an overall decrease among several thousand people participating in a study at a hot springs resort. Similar results have been observed for parameters of the autonomic nervous [15] and endocrine [16] systems after serial immersion in a hot springs. Therefore, increases or decreases in the Tscores for each POMS scale component, following serial BB, were not compared. Rather, convergence of the T- 
scores on the 50-point mark was examined. Thus, this is the first study comparing mood states using a $\Delta 50$ value.

Previous reports have described the effects of dry sauna bathing and whole body warming (i.e., Waon therapy) as increasing the deep body temperature [17]-[19]. Repeated Waon therapy also improved the anger score of patients with chronic pain [20]. Waon therapy involves 15 min of dry sauna bathing at $60^{\circ} \mathrm{C}$ and maintaining body warmth for an additional 30 min while in a static supine position, wrapped in a blanket, after bathing.

Iiyama et al. [21] examined the effects of a 10 -min bath in warm $\left(41^{\circ} \mathrm{C}\right)$ tap water, followed by maintaining body warmth for $30 \mathrm{~min}$ while in a static supine position, wrapped in a blanket. In their study, the participants' sublingual temperatures were significantly raised from $36.3^{\circ} \mathrm{C} \pm 0.39^{\circ} \mathrm{C}$ to $37.2^{\circ} \mathrm{C} \pm 0.15^{\circ} \mathrm{C}$ for 40 min after bathing. Similarly, BBH with extracts containing cnidii rhizoma and aurantii nobilis pericarpium maintained a raised sublingual temperature for 30 min after bathing [9]. The herbal extract contained angelicae radix and aurantii nobilis pericarpium extracts, which maintained significant raised forearm skin temperatures, even 60 min after bathing [7].

Brain regions, such as the amygdala and nucleus accumbens, are related to emotion in higher vertebrate animals, including humans. Given this association, Okada [22] examined the effects of bathing on central neurotransmitter levels in rats to determine a physiological relationship between warm baths and mental functioning. The results showed that dopamine metabolism and neurotensin-like immunoreactivity in the amygdala and nucleus accumbens changed significantly after 10 -min baths in warm $\left(40^{\circ} \mathrm{C}\right)$ tap water, but not after 10 -min baths in lukewarm $\left(34^{\circ} \mathrm{C}\right)$ tap water. From these results, thermal action was assumed to affect central neurotransmitter (i.e., mental functioning) after bathing in warm tap water, rather than hydrostatic pressure of warm or lukewarm tap water.

In our studies, the Anger-Hostility score significantly converged on the 50-point mark postBBW, compared with preBBW (i.e., after a period of showering); similar results were seen postBBH, compared with preBBH (again, after a period of showering). These results indicate that the Anger-Hostility mental state might be influenced by the elevated deep body temperatures following BBW and BBH (angelicae radix, aurantii nobilis pericarpium, and zingiberis rhizoma have vasodilatory action). Thus, a normalizing phenomenon associated with mental condition appears to have occurred.

Chamomile-like fragrance was provided in the herbal extract.Amsterdum et al. [23] reported that chamomile has an antidepressant activity in depressed people. They reported a significantly greater reduction in the mean total Hamilton Depression Rating (HAM-D) score and HAM-D core depression item score following chamomile treatment versus placebo in depressed participants. Pinto et al. [24] reported that chamomile had an effect in an animal depression model. Specifically, in a forced swimming test, a total leukocyte count decrease was observed in the chamomile-treated group. Similarly, Takamatsu et al. [25] reported that the color of a solution can influence participant mental conditions. Specifically, green, green-yellow, and yellow-red provide comforting and calming psychological effects. The color of the herbal extracts added to the baths, in our experiment 2 , was a green-yellow. Thus, the chamomile-like fragrance was considered to possibly influence the Depression-Dejection and Fatigue scores and/or that the color of the added herbal extract might influence these scales.

A POMS questionnaire survey of 189 middle-aged Japanese individuals, conducted by Ishizawa et al. [4], revealed that frequent BB ( $\geq 3$ times per week) affected participant Tension-Anxiety scores. In our studies, involving young adults, the $\Delta 50$ in the Tension-Anxiety scores of the BB session demonstrated different results in experiment $1(\mathrm{P}=0.043)$ than in experiment $2(\mathrm{P}=0.458)$, the $\mathrm{P}$-values were dissociated from each other. Although the Tension-Anxiety $\mathrm{P}$-value in experiment $1(\mathrm{P}=0.043)$ reached statistical significance, there is a need for further investigation to determine whether it had the potential to produce false positives.

Different results for the Confusion change rates were observed between experiments $1(\mathrm{P}=0.011)$ and $2(\mathrm{P}=$ 0.055). The Confusion $P$-value in experiment $2(\mathrm{P}=0.055)$ was very nearly statistically significant, and might have reached the $5 \%$ level of significance with a larger sample size. In the BB session, the Confusion change was positive in experiment 1 , but negative in experiment 2. Previous studies have not revealed a significant difference in Confusion. Therefore, further investigation is necessary.

These studies have several limitations. Similar conditions of temperature, humidity, lighting, and wall design may not have existed within each participant's home bathroom. Additionally, events happening in each participant's daily life were not controlled in either experiment 1 or 2 . Further, there may have been variations in room temperatures during the period that the individuals were directed to remain warm following bathing in experiment 1. Additionally, there may have been differences in the herbal extract concentrations in each participant's 
home bathtub in experiment 2. Furthermore, another limitation was the very small study population.

\section{Conclusion}

These studies investigated changing bathing styles from showering to BB; the effects of $\mathrm{BB}$, maintaining warmth with an insulated sheet and sleeping bag after BB; and BB with herbal extracts, on the mental condition of healthy young adults were investigated. Raising the deep body temperature following BBW and BBH had a salutary influence on Anger-Hostility, and provided advantages over shower bathing for improving the mental fitness of healthy young adults.

\section{Acknowledgements}

These studies were carried out with the financial support of Bathclin Corporation.

\section{References}

[1] Patel, V., Flisher, A.J., Hetrick, S. and McGorry, P. (2007) Mental Health of Young People: A Global Public-Health Challenge. Lancet, 369, 1302-1312. http://dx.doi.org/10.1111/j.1365-2214.2007.00778_2.x

[2] Hunt, J. and Eisenberg, D (2010) Mental Health Problems and Help-Seeking Behavior among College Students. Journal of Adolescent Health, 46, 3-10. http://dx.doi.org/10.1016/j.jadohealth.2009.08.008

[3] Uchida, C. (2010) Apathetic and Withdrawing Students in Japanese Universities-With Regard to Hikikomori and Student Apathy. Journal of Medical and Dental Sciences, 57, 95-108.

[4] Ishizawa, T., Watanabe, S., Yano, S., Aburada, M., Miyamoto, K. and Ojima, T. (2012) Relationship between Bathing Habits and Physical and Psychological State. Journal of the Japanese Society of Balneology, Climatology and Physical Medicine, 75, 227-237.

[5] Hayasaka, S., Shibata, Y., Goto, Y., Noda, T. and Ojima, T. (2010) Bathing in a Bathtub and Health Status: A CrossSectional Study. Complementary Therapies in Clinical Practice, 16, 219-221. http://dx.doi.org/10.1016/j.ctcp.2010.05.002

[6] Ito, F., Furuya, K., Takagi, T., Motoki, Y. and Kiyama, T. (1982) Clinical Studies Of Physiological Effects of Natril Sulfas Siccatus Spring with Herbal Extract. Journal of the Japanese Society of Balneology, Climatology and Physical Medicine, 46, 84-92.

[7] Watanabe, S., Imanishi, N., Fujiwara, T., Kawasaki, Y. and Ohtsuka, Y. (1998) Effects of Bathing with Cutting Crude Drugs. Journal of the Japanese Society of Balneology, Climatology and Physical Medicine, 61, 135-140.

[8] Yorozu, H. and Komoto, Y. (1992) The Effect of Crude Drug Extracts Bathing. Journal of the Japanese Society of Balneology, Climatology and Physical Medicine, 55, 105-112.

[9] Horikiri, Y., Hiyoshi, T., Kawahira, K., Tanaka, N., Watanabe, S., Fujiwara, T. and Kawasaki, Y. (1998) Circulatory Effects of Bath Agent with Senkyu and Chimpi Extract in Healthy Men. Journal of the Japanese Society of Balneology, Climatology and Physical Medicine, 61, 95-100. (In Japanese)

[10] Takehara, H., Yanase, T., Nishikawa, K. and Murakami, K. (2001) The Survey on Bathroom Environment and Residential Consciousness (Part 2). On the Residential Consciousness and Interest in Bathing. Journal of Home Economics of Japan, 52, 1005-1013. (In Japanese)

[11] Iiyama, J., Horikiri, Y., Kawahira, K. and Tanaka, N. (2003) The Effects of Warm Water Bathing on Renal Function. Journal of the Japanese Society of Balneology, Climatology and Physical Medicine, 66, 85-90.

[12] Jordan, H. (1966) Balneotherapie und Blutdruck-biometrisch betrachtet. Zeitschrift für angewandte Bäder- und Klimaheilkunde, 13, 380-389. (In German)

[13] Jordan, H. and Wagner, H. (1969) Reaktionen der Puls- und Atemfrequenz auf einen Klimareiz an Hand der Streuung der täglichen Änderungen. Zeitschrift für angewandte Bäder- und Klimaheilkunde, 16, 404-409. (In German)

[14] Jordan, H. (1970) Normalization Effect of Health Resort Therapy, a Biometric Problem. Archiv für Physikalische Therapie, 22, 3-8. (In German)

[15] Yoshizaki, H., Suzuki, J. and Muranaka, M. (1988) Changes of Cardiovascular Parameters during Serial Immersion in Hot Springs. Journal of the Japanese Society of Balneology, Climatology and Physical Medicine, 51, 181-193. (In Japanese)

[16] Taguchi, F., Suzuki, S., Monou, H., Itoh, N., Yoshizaki, H. and Kogure, T. (1986) Changes of Plasma Catecholamine Concentration during Serial Immersion in Hot Springs, Special Reference to the Relationships with Efficacy of Balneotherapy. Journal of the Japanese Society of Balneology, Climatology and Physical Medicine, 49, 131-138. (In Jap- 
anese)

[17] Tei, C., Horikiri, Y., Park, J.C., Jeong, J.W., Chang, K.S., Toyama, Y. and Tanaka, N. (1995) Acute Hemodynamic Improvement by Thermal Vasodilation in Congestive Heart Failure. Circulation, 91, 2582-2590. http://dx.doi.org/10.1161/01.CIR.91.10.2582

[18] Imamura, M., Biro, S., Kihara, T., Yoshifuku, S., Takasaki, K., Otsuji, Y., Minagoe, S., Toyama, Y. and Tei, C. (2001) Repeated Thermal Therapy Improves Impaired Vascular Endothelial Function in Patients with Coronary Risk Factors. Journal of the American College of Cardiology, 38, 1083-1088. http://dx.doi.org/10.1016/S0735-1097(01)01467-X

[19] Kihara, T., Biro, S., Imamura, M., Yoshifuku, S., Takasaki, K., Ikeda, Y., Otuji, Y., Minagoe, S., Toyama, Y. and Tei, C. (2002) Repeated Sauna Treatment Improves Vascular Endothelial and Cardiac Function in Patients with Chronic Heart Failure. Journal of the American College of Cardiology, 39, 754-759. http://dx.doi.org/10.1016/S0735-1097(01)01824-1

[20] Masuda, A., Koga, Y., Hattanmaru, M., Minagoe, S. and Tei, C. (2005) The Effects of Repeated Thermal Therapy for Patients with Chronic Pain. Psychotherapy and Psychosomatics, 74, 288-294. http://dx.doi.org/10.1159/000086319

[21] Iiyama, J., Horikiri, Y., Kawahira, K. and Tanaka, N. (2007) Effects of Whole Body Warm Water Immersion on Indocyanine Green (ICG) Excretion Test in Healthy Human. Journal of the Japanese Society of Balneology, Climatology and Physical Medicine, 70, 215-222.

[22] Okada, A. (1991) Hot Water Bathing and Neurotransmitters. Journal of the Japanese Society of Balneology, Climatology and Physical Medicine, 55, 3-9. (In Japanese)

[23] Amsterdam, J.D., Shults, J., Soeller, I., Mao, J.J., Rockwell, K. and Newberg, A.B. (2012) Chamomile (Matricaria recutita) May Have Antidepressant Activity in Anxious Depressed Humans: An Exploratory Study. Alternative Therapies in Health and Medicine, 18, 44-49.

[24] Pinto, S.A., Bohland, E., Coelho, C.P., Morgulis, M.S. and Bonamin, L.V. (2008) An Animal Model for the Study of Chamomilla in Stress and Depression: Pilot Study. Homeopathy, 97, 141-144. http://dx.doi.org/10.1016/j.homp.2008.04.001

[25] Takamatsu, M., Nakashima, Y., Qian, L. and Katoh, Z. (2009) Study on Quantification of Mental Effect by Hue of Solution. Transactions of Japan Society of Kansei Engineering, 8, 799-804. (In Japanese) 
Scientific Research Publishing (SCIRP) is one of the largest Open Access journal publishers. It is currently publishing more than 200 open access, online, peer-reviewed journals covering a wide range of academic disciplines. SCIRP serves the worldwide academic communities and contributes to the progress and application of science with its publication.

Other selected journals from SCIRP are listed as below. Submit your manuscript to us via either submit@scirp.org or Online Submission Portal.
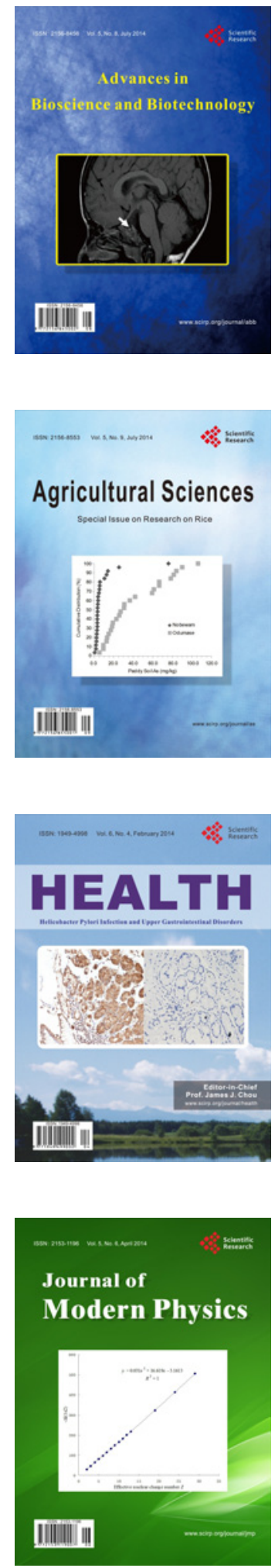
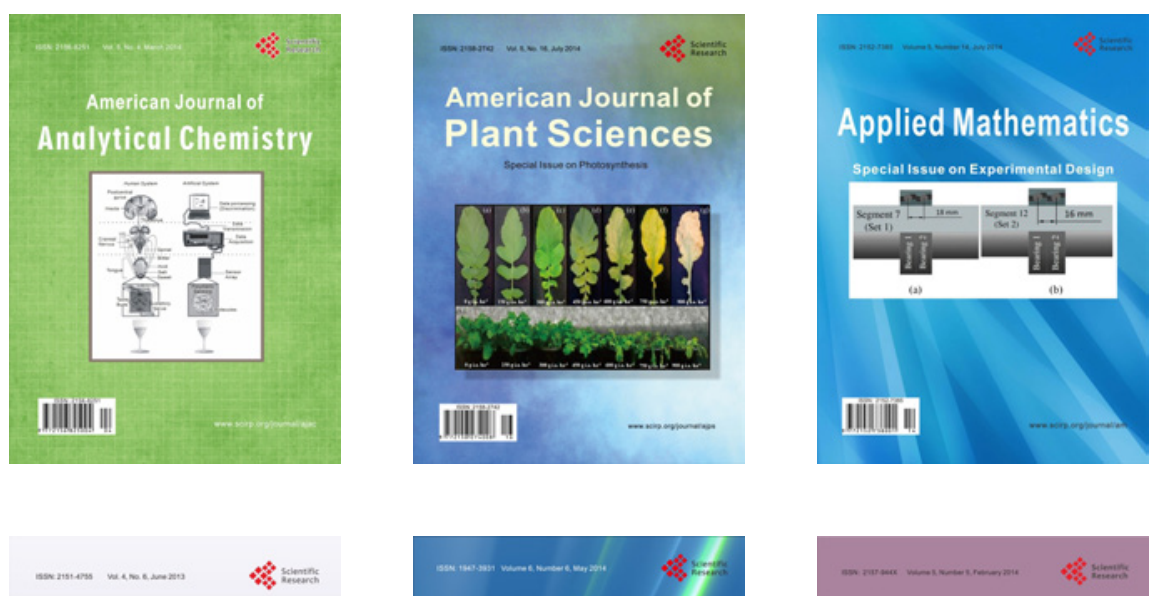

Creative Education
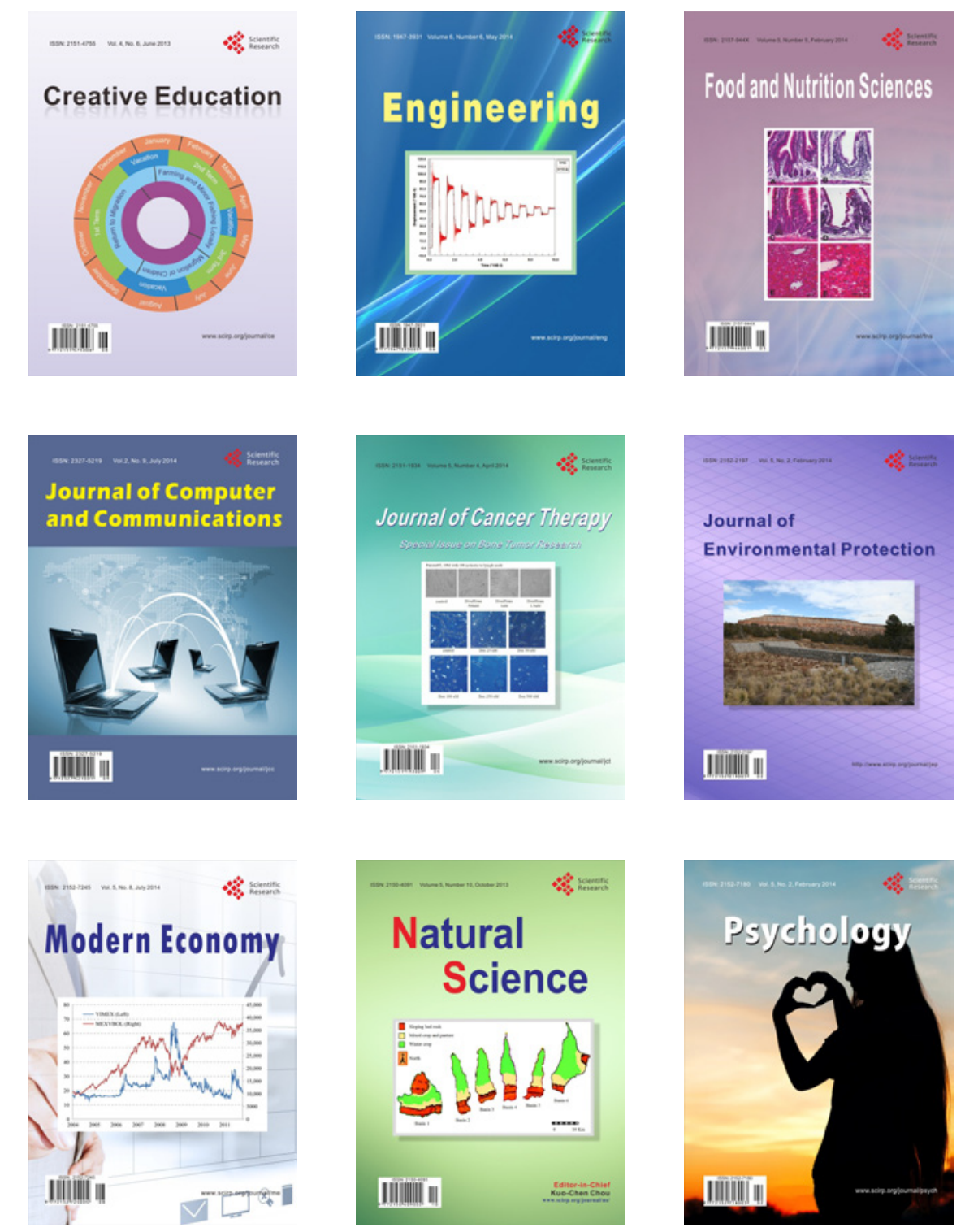